\title{
The proliferative effects of Pyropia yezoensis peptide on IEC-6 cells are mediated through the epidermal growth factor receptor signaling pathway
}

\author{
MIN-KYEONG LEE ${ }^{1}$, IN-HYE KIM ${ }^{2}$, YOUN-HEE CHOI ${ }^{2}$, JEONG-WOOK CHOI $^{1}$, \\ YOUNG-MIN KIM ${ }^{2}$ and TAEK-JEONG NAM ${ }^{1,2}$ \\ ${ }^{1}$ Department of Food Science and Nutrition, Pukyong National University, Busan 608-737; \\ ${ }^{2}$ Institute of Fisheries Science, Pukyong National University, Busan 619-911, Republic of Korea
}

Received December 1, 2014; Accepted February 16, 2015

DOI: 10.3892/ijmm.2015.2111

\begin{abstract}
For a number of years, seaweed has been used as a functional food in Asian countries, particularly in Korea, Japan and China. Pyropia yezoensis is a marine red alga that has potentially beneficial biological activities. In this study, we examined the mechanisms through which a Pyropia yezoensis peptide [PYP1 (1-20)] induces the proliferation of IEC-6 cells, a rat intestinal epithelial cell line, and the involvement of the epidermal growth factor receptor (EGFR) signaling pathway. First, cell viability assay revealed that PYP1 (1-20) induced cell proliferation in a concentration-dependent manner. Subsequently, we examined the mechanisms responsible for this induction of proliferation induced by PYP1 (1-20). EGFR is widely expressed in mammalian epithelial tissues, and the binding of this ligand affects a variety of cell physiological parameters, such as cell growth and proliferation. PYP1 (1-20) increased the expression of EGFR, Shc, growth factor receptorbound protein 2 (Grb2) and son of sevenless (SOS). EGFR also induced the activation of the Ras signaling pathway through Raf, MEK and extracellular signal-regulated kinase (ERK) phosphorylation. In addition, cell cycle analysis revealed the expression of cell cycle-related proteins. The results demonstrated an increased number of cells in the G1 phase and an enhanced cell proliferation. In addition, the upregulation of cyclin D, cyclin E, Cdk2, Cdk4 and Cdk6 was observed accompanied by a decreased in p21 and p27 expression. These findings suggest that PYP1 (1-20) stimulates the proliferation of rat IEC-6 cells by activating the EGFR signaling pathway. Therefore, PYP1 (1-20) may be a potential source for the development of bio-functional foods which promotes the proliferation of intestinal epithelial cells.
\end{abstract}

Correspondence to: Professor Taek-Jeong Nam, Department of Food Science and Nutrition, Pukyong National University, 599-1 Daeyeon 3-Dong, Nam-gu, Busan 608-737, Republic of Korea

E-mail: namtj@pknu.ac.kr

Key words: Pyropia yezoensis, peptide, proliferation, epidermal growth factor receptor, signaling pathway, cell cycle

\section{Introduction}

Seaweed is widely consumed throughout Asian countries, such as China, Japan, Korea, Vietnam, Indonesia, the Philippines and Hawaii, as a natural medicinal and food source (1). Seaweed contains a variety of nutrients, such as carbohydrates, vitamins, minerals, fatty acids, dietary fiber, amino acids, iodine and essential polysaccharides. Research on the chemical and nutritional composition of seaweed has revealed that it has antioxidant, antitumor and antibacterial activities $(2,3)$. The red seaweed, Pyropia yezoensis, is an economically important seaweed in Asian countries, such as China, Japan and Korea. Pyropia yezoensis is an important source of physiologically active substances that contain 25-50\% protein and 25-40\% carbohydrates based on dry matter weight (4). Pyropia yezoensis has been shown to exert biological effects, such as antitumor, antifatigue, blood pressure-reducing, anti-inflammatory, antioxidant and hepatoprotective effects $(5,6)$. In a previous study, we examined a peptide from Pyropia yezoensis which stimulates the proliferation of IEC- 6 cells by activating the insulin-like growth factor I receptor signaling pathway (7). In the present study, we examined the effects of a Pyropia yezoensis peptide [PYP1 (1-20)] on cell proliferation and related EGFR signaling pathways in IEC-6 cells, a rat intestinal epithelial cell line.

Cell proliferation is induced through intracellular signal transduction mediated by receptor tyrosine kinases (RTKs), such as epidermal growth factor receptor (EGFR) (8). RTKs are cell membrane receptors for growth factors and other extracellular ligands. RTKs mediate cellular tyrosine phosphorylation and regulate intracellular signaling pathways, such as those involved in cell migration, differentiation and proliferation (9-11). RTKs of the EGFR family mediate essential cellular functions, including the regulation of cellular proliferation, growth, survival, migration, differentiation and development in normal and pathological states $(12,13)$. The binding of EGF to EGFR initiates a number of molecular events. The EGF-EGFR molecular interaction activates growth-promoting signals primarily through the activation of Ras, leading to activation of the Ras/Raf/mitogen-activated protein kinase (MAPK) and phosphoinositide 3-kinase (PI3K)/Akt pathways, as well as many others $(14,15)$. EGFR is stimulated by the guanine nucle- 
otide-exchange factor, son of sevenless (SOS)-growth factor receptor bound protein 2 (Grb2) complex. This activation of EGFR leads to the activation of Ras. The Src homology 2 (SH2) domain of Grb2 binds to autophosphorylation sites of EGFR, including Y1068, and several other receptors. The SH3 domains of Grb2 bind to the proline-rich C-terminal domain of SOS, a guanine nucleotide exchange factor (GEF) for Ras. In this way, the SOS-Grb2 interaction plays a critical role in regulating the activation of Ras $(16,17)$. The small guanosine triphosphatase protein Ras/MAPK signaling pathway is essential for the regulation of a variety of biological processes, such as cell growth, cell cycle, cell proliferation and cell senescence, all of which are important for normal development (18). It consists of a core module of three kinases comprising Raf, MEK and extracellular signal-regulated kinase (ERK) that transmit signals downstream of the small GTPase, Ras. GTP-loaded Ras triggers the sequential activation of Raf, MEK and ERK to promote cell survival and various cellular functions (19,20). Therefore, EGFR and related proteins are attractive targets affecting cell proliferation.

The present study was carried out to confirm that PYP1 (1-20) promotes the proliferation of IEC-6 cells and to determine the molecular mechanisms responsible for its proliferative effects by investigating the involvement of the EGFR signaling pathway. Our findings suggest that PYP1 (1-20) affects EGFR-induced cell proliferation, a potential factor in intestinal epithelial cell protection.

\section{Materials and methods}

Pyropia yezoensis peptide synthesis. The N-terminal 20 residues of PYP1 (1-20) (A-L-E-G-G-K-S-S-G-G-G-E-A-TR-D-P-E-P-T), designated as PYP1 (1-20), were synthesized by Peptron (Daejeon, Korea) (7,21). The purification of PYP1 (1-20) was performed using a Shimadzu Prominence high-performance liquid chromatography (HPLC) apparatus and the software package Class-VP, 6.14 (Shimadzu, Kyoto, Japan), with a C18 column (Shiseido Capcell Pak; Shiseido, Tokyo, Japan) in $0.1 \%$ TFA/water, a gradient of $10-70 \%$ acetonitrile in $0.1 \%$ TFA, a flow rate of $1 \mathrm{ml} / \mathrm{min}$, and UV detection at $220 \mathrm{~nm}$. The molecular mass of PYP1 (1-20) was confirmed to be $1,916 \mathrm{Da}$ (matched with the sequence mass) by mass spectrometric analysis (HP 1100 Series LC/MSD) (21).

Cell culture. The IEC-6 rat small intestinal epithelial cells (ATCC CRL-1592; ATCC, Manassas, VA, USA) were cultured in Dulbecco's modified Eagle's medium (DMEM) supplemented with $10 \%$ fetal bovine serum (FBS; HyClone, Inc., South Logan, UT, USA), $100 \mathrm{U} / \mathrm{ml}$ penicillin and $100 \mathrm{mg} / \mathrm{ml}$ streptomycin, at a temperature of $37^{\circ} \mathrm{C}$ in a humidified atmosphere of $5 \% \mathrm{CO}_{2}$. The cells were cultured to $60 \%$ confluence in $100-\mathrm{mm}$ dishes. The medium was replaced every 2 days.

MTS assay. The effects of various PYP1 (1-20) concentrations on cellproliferationweredeterminedcolorimetrically after 24 husing the 3-(4,5-dimethylthiazol-2-yl)-5-(3-carboxymethoxyphenyl)2-(4-sulfonyl)-2H-tetrazolium (MTS) assay with the Cell Titer 96 Aqueous One Solution reagent (Promega, Madison, WI, USA). The cells were seeded in 96-well plates at $1 \times 10^{4}$ cells/ well. After $24 \mathrm{~h}$ of incubation, the cells were maintained in serum-free medium (SFM) for $4 \mathrm{~h}$. The medium was replaced with fresh SFM containing PYP1 (1-20), and the cells were incubated for an additional $24 \mathrm{~h}$. The cells were exposed to MTS assay solution at $37^{\circ} \mathrm{C}$ for $30 \mathrm{~min}$, and the optical density at $490 \mathrm{~nm}$ was measured using a microplate reader. The $\mathrm{OD}_{490}$ values of the control cells were designated as $100 \%$.

Western blot analysis. To prepare whole cell extracts, the IEC-6 cells in 100-mm dishes were cultured to 50-60\% confluence and then incubated in SFM for $4 \mathrm{~h}$. Fresh SFM containing PYP1 (1-20) $(125,250,500$ and 1,000 ng/ml) was added to the cells and incubated another $24 \mathrm{~h}$, after which the cells were washed with phosphate-buffered saline (PBS) and suspended in extraction buffer $(50 \mathrm{mM}$ Tris- $\mathrm{HCl}, \mathrm{pH} 7.4$, $150 \mathrm{mM} \mathrm{NaCl}, 0.25 \%$ Na-deoxycholate, $1 \% \mathrm{NP}-40$ and $1 \mathrm{mM}$ EGTA) containing protease inhibitors $\left(1 \mathrm{mM} \mathrm{Na}_{3} \mathrm{VO}_{4}, 1 \mu \mathrm{g}\right.$ / $\mathrm{ml}$ aprotinin, $1 \mu \mathrm{g} / \mathrm{ml}$ pepstatin, $1 \mu \mathrm{g} / \mathrm{ml}$ leupeptin, $1 \mathrm{mM}$ $\mathrm{NaF}$ and $1 \mathrm{mM}$ PMSF) on ice. The extracts were centrifuged at 14,000 rpm for $10 \mathrm{~min}$, and the supernatant was used in western blot analysis. Boiling sample buffer $(30 \mu \mathrm{g})$ was added to the total cell lysate, and the samples were boiled for $10 \mathrm{~min}$ at $100^{\circ} \mathrm{C}$. Proteins were separated by $7.5-12.5 \%$ sodium dodecyl sulfate-polyacrylamide gel electrophoresis (SDS-PAGE) and transferred onto polyvinylidene fluoride membranes (Millipore, Billerica, MA, USA). The membranes were blocked for $1 \mathrm{~h} 40 \mathrm{~min}$ at room temperature in blocking buffer [1\% bovine serum albumin (BSA) in TBS-T]. The blots were probed with primary antibodies [p-EGFR (sc-12351), EGFR (sc-03), Shc (sc-1695), Grb2 (sc-255), SOS (sc-259), Ras (\#3965), Raf (sc-227), MEK (sc-219), p-ERK (sc-7383), ERK (sc-94), Cyclin D1 (sc-753), Cyclin E (sc-481), Cdk2 (sc-163), Cdk4 (sc-601), Cdk6 (sc-177), pRb (sc-16670), p21 (sc-397), p27 (sc-528), GAPDH (sc-25778) (1:1,000 and 1:2,000 in 1\% BSA/ TBS-T)] overnight at $4^{\circ} \mathrm{C}$. The membranes were then washed twice for $15 \mathrm{~min}$ in TBS-T. The secondary antibody was a horseradish peroxidase (HRP)-conjugated goat anti-mouse or rabbit antibody [goat anti-mouse IgG-HRP (sc-2031), goat antirat IgG-HRP (sc-2032) (1:10,000 in 1\% BSA/TBS-T)]. Signal bands were detected using an enhanced chemiluminescence (ECL) western blotting kit (Thermo Fisher Scientific, Inc., Rockford, IL, USA).

Reverse transcription-polymerase chain reaction ( $R T-P C R)$. The mRNA expression levels of specific genes were evaluated by RT-PCR (22). The IEC- 6 cells were seeded into $100-\mathrm{mm}$ dishes at a density of $2 \times 10^{4}$ cells/well and cultured for $24 \mathrm{~h}$, after which the medium was replaced with SFM containing PYP1 (1-20) $(125,250,500$ and 1,000 ng/ml) for $24 \mathrm{~h}$. Total RNA was isolated from the cells using TRIzol reagent (Invitrogen Co., Carlsbad, CA, USA) and converted to cDNA using oligo(dT) primers (Intron Biotechnology Inc., Seongnam, Korea). For PCR amplification, the cDNA and specific primers (Table I) were added to $2 \mathrm{X}$ TOPsimple ${ }^{\mathrm{TM}}$ DyeMIX-nTaq (Enzynomics, Inc., Daejoen, Korea) and 0.1\% diethylpyrocarbonate (DEPC) water. The amplified products were analyzed on $1 \%$ agarose gels stained with RedSafe ${ }^{\mathrm{TM}}$ nucleic acid staining solution (Intron Biotechnology, Inc.).

Treatment with a MEK inhibitor (PD98059). The MEK inhibitor, PD98059 was obtained from Cell Signaling Technology (Beverly, MA, USA) and stored as a $20 \mathrm{mM}$ stock solution at 
Table I. Oligonucleotide sequences of the primers used in RT-PCR.

\begin{tabular}{|c|c|}
\hline $\begin{array}{l}\text { Gene } \\
\text { name }\end{array}$ & Primer sequences $\left(5^{\prime} \rightarrow 3^{\prime}\right)$ \\
\hline EGFR & $\begin{array}{l}\text { F: CTC-ACG-CAG-TTG-GGC-ACT-TT } \\
\text { R: TCA-TGG-GCA-GCT-CCT-TCA-GT }\end{array}$ \\
\hline SOS1 & $\begin{array}{l}\text { F: GCA-TCT-TAT-TGG-AAG-GAT-TT } \\
\text { R: CCT-CTC-AGG-TGA-GAC-TGC-TA }\end{array}$ \\
\hline Grb2 & $\begin{array}{l}\text { F: CGG-GAT-CAT-GGA-AGC-CAT-GGC-CAA-A } \\
\text { R: CTA-GCT-AGC-TTA-GAC-GTT-CCG-GTT-CAC-TG }\end{array}$ \\
\hline Ras & $\begin{array}{l}\text { F: CCC-GTC-CTC-ATG-TAC-TGG-TC } \\
\text { R: ATC-TTG-GAT-ACG-GCA-GGT-CA }\end{array}$ \\
\hline Raf & $\begin{array}{l}\text { F: AAG-GCA-GTC-GTG-CAA-GCT-CA } \\
\text { R: GAT-GAT-GGC-AAA-CTC-ACG-GAT-TG }\end{array}$ \\
\hline MEK & $\begin{array}{l}\text { F: CGA-TGG-ATC-CCC-CAA-GAA-GAA-GCC-GAC-G } \\
\text { R: CGA-TCT-CGA-GTT-AGA-CGC-CAG-CAG-CAT-G }\end{array}$ \\
\hline GAPDH & $\begin{array}{l}\text { F: CAG-CCG-AGC-CAC-ATC-G } \\
\text { R: TGA-GGC-TGT-TGT-CAT-ACT-TCT-C }\end{array}$ \\
\hline
\end{tabular}

RT-PCR, reverse transcription-polymerase chain reaction; EGFR, epidermal growth factor receptor; SOS1, son of sevenless; Grb2, growth factor receptor bound protein 2; GAPDH, glyceraldehyde 3-phosphate dehydrogenase; F, forward; $\mathrm{R}$, reverse.

$-20^{\circ} \mathrm{C}$. The cells were pre-treated with $40 \mu \mathrm{M}$ PD98059 for $1 \mathrm{~h}$ and then incubated for $24 \mathrm{~h}$ as described above.

Cell cycle analysis. The cells were cultured in 6-well plates to $50-60 \%$ confluence and treated with SFM or various doses of PYP1 (1-20) $(125,250,500$ and 1,000 ng/ml) for $24 \mathrm{~h}$. The cells were harvested after trypsinization, washed with PBS, and treated with cold PI solution $(50 \mu \mathrm{g} / \mathrm{ml})$ containing RNase A $(0.1 \mathrm{mg} / \mathrm{ml})$ in PBS (pH 7.4) for $30 \mathrm{~min}$ in the dark. Flow cytometry was performed using a FACSCalibur instrument (Becton-Dickinson, San Jose, CA, USA).

Statistical analysis. Multiple mean values were compared using analysis of variance with SPSS (SPSS Inc., Chicago, IL, USA). Values are the means $\pm \mathrm{SD}$. Different letters were used to indicate significant values according to Duncan's multiple range test.

\section{Results}

PYP1 (1-20) increases the expression of EGFR and EGFRrelated proteins. To investigate the mechanisms responsible for the PYP1 (1-20)-induced proliferation of IEC-6 cells, we examined the effects of PYP1 (1-20) on EGFR signalingrelated proteins. The protein and mRNA expression levels of phoshorylated (p-)EGFR, Shc, Grb2 and SOS in the IEC-6 cells treated with PYP1 (1-20) $(125,250,500$ and 1,000 ng/ml) for $24 \mathrm{~h}$ were measured by western blot analysis and RT-PCR. Treatment with PYP1 (1-20) upregulated the protein (Fig. 1A) and mRNA (Fig. 1B) expression levels of p-EGFR, Shc, Grb2 and SOS in a dose-dependent manner. These results indicate that PYP1 (1-20) promotes the expression of EGFR signalingrelated molecules.

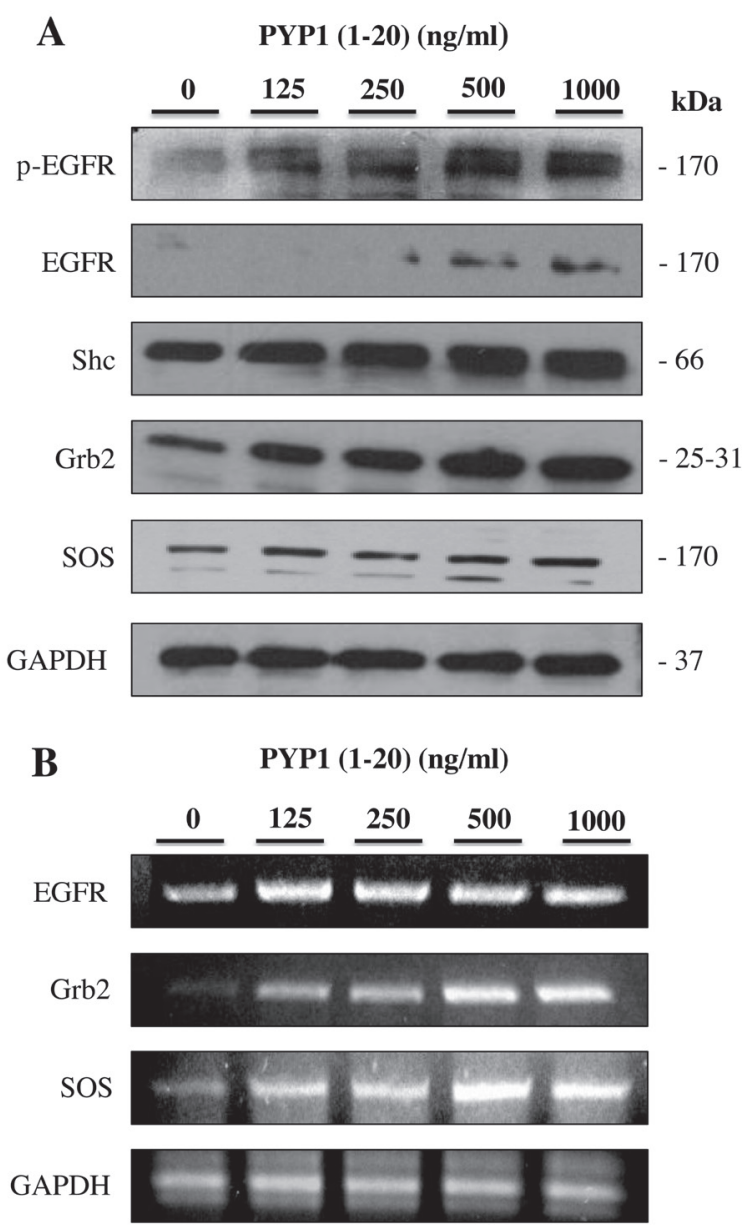

Figure 1. Effect of treatment with Pyropia yezoensis peptide [PYP1 (1-20)] on epidermal growth factor receptor (EGFR), Shc, growth factor receptor bound protein 2 (Grb2) and son of sevenless (SOS) protein and mRNA expression levels in IEC-6 cells. Proteins were subjected to western blot analysis and cDNA was subjected to RT-PCR. (A) Protein expression levels were increased upon incubation with PYP1 (1-20) for $24 \mathrm{~h}$. (B) mRNA expression levels were also increased, as demonstrated by RT-PCR.

PYP1 (1-20) induces the activation of the Ras-p42/p44 MAPK signaling pathway. To further determine the downstream signals regulated by EGFR activation, the protein and mRNA expression levels of the Ras-p42/p44 signaling pathway members were measured in the IEC- 6 cells. The IEC- 6 cells were treated with PYP1 (1-20) (125, 250, 500 and 1,000 ng/ $\mathrm{ml}$ ) for $24 \mathrm{~h}$ and then subjected to western blot analysis and RT-PCR. Treatment with PYP1 (1-20) for $24 \mathrm{~h}$ resulted in increased protein (Fig. 2A) and mRNA (Fig. 2B) expression levels of Ras, Raf, MEK and p-ERK compared with the untreated controls. These results indicate that PYP1 (1-20) activates the Ras-p42/p44 MAPK signaling pathway in IEC-6 cells.

Pre-treatment with MEK inhibitor suppresses the PYP1 (1-20)induced cell proliferation. To investigate the suppressive effect of the MEK inhibitor (PD98059) on PYP1 (1-20)-induced cell proliferation, an MTS assay was performed. Pre-treatment with PD98059 for $1 \mathrm{~h}$, followed by the addition of PYP1 (1-20) $(500 \mathrm{ng} / \mathrm{ml})$ for $24 \mathrm{~h}$, induced a decrease in cell viability identical to that of the controls (Fig. 3). Thus, EGFR is a target of PYP1 (1-20)-induced cell proliferation. 


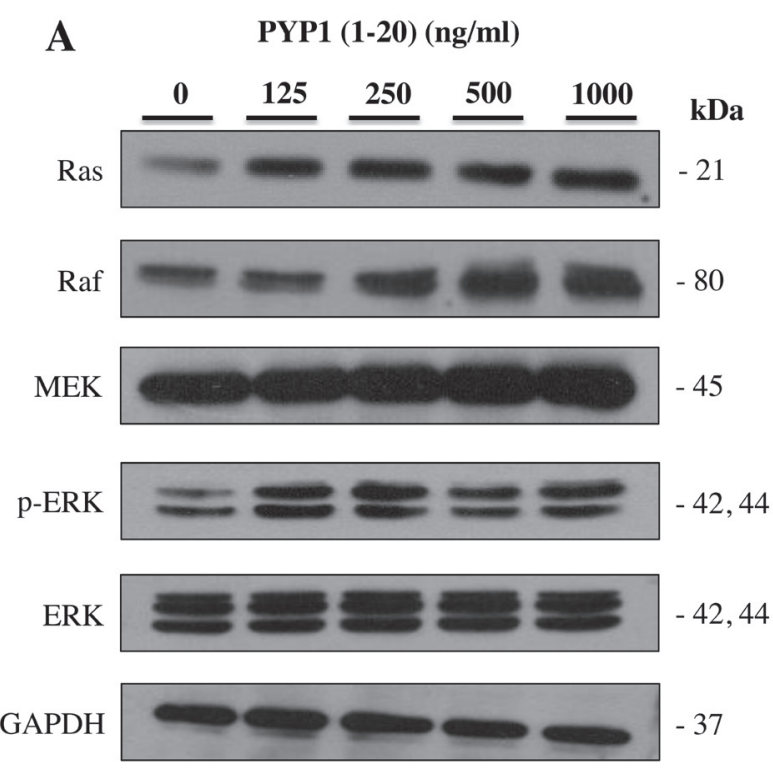

B PYP1 (1-20) $(\mathrm{ng} / \mathrm{ml})$

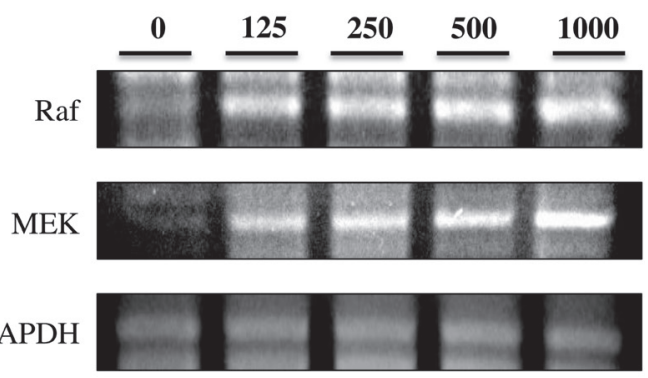

Figure 2. Effects of treatment with Pyropia yezoensis peptide [PYP1 (1-20)] on Ras, Raf, MEK and ERK (A) protein and (B) mRNA expression levels in IEC-6 cells. Whole cell extracts were prepared and analyzed by western blot analysis using anti-Ras, anti-Raf, anti-MEK, anti-phosphorylated-ERK, anti-ERK and anti-glyceraldehyde 3-phosphate dehydrogenase (GAPDH) antibodies.

Effect of PYP1 (1-20) on cell cycle progression. The percentage of cells at each phase of the cell cycle was examined by flow cytometry. The cell cycle response was determined in the cells treated with various concentration $(125,250,500$ and 1,000 ng/ $\mathrm{ml})$ of PYP1 (1-20) for $24 \mathrm{~h}$. Treatment with PYP1 (1-20) increased the percentage of IEC- 6 cells in the G1 phase (47.6, 50.6, 56.8, 62.8 and $64.4 \%$ following treatment with $0,125,250$, 500 and $1,000 \mathrm{ng} / \mathrm{ml}$ PP-YE, respectively) in a dose-dependent manner (Fig. 4). Therefore, treatment with PYP1 (1-20) markedly increased the proportion of cells in the G1 phase, suggesting that PYP1 (1-20) promotes IEC-6 cell cycle progression.

Effect of PYPI (1-20) on the expression of cell cycle-related proteins. The regulation of cell proliferation is defined as the increase in the cell number resulting from the completion of the cell cycle (23). To confirm the cell proliferation mechanisms through which PYP1 (1-20) promotes cell cycle progression, we examined the cell cycle-related protein content. The expression levels of cyclin D1, cyclin E, Cdk2, Cdk4, Cdk6, pRb, p21 and p27 were measured by western blot analysis using specific antibodies. The IEC-6 cell cycle response was determined following treatment with PYP1 (1-20) at various concentrations $(125,250,500$ and $1,000 \mathrm{ng} / \mathrm{ml})$. The protein

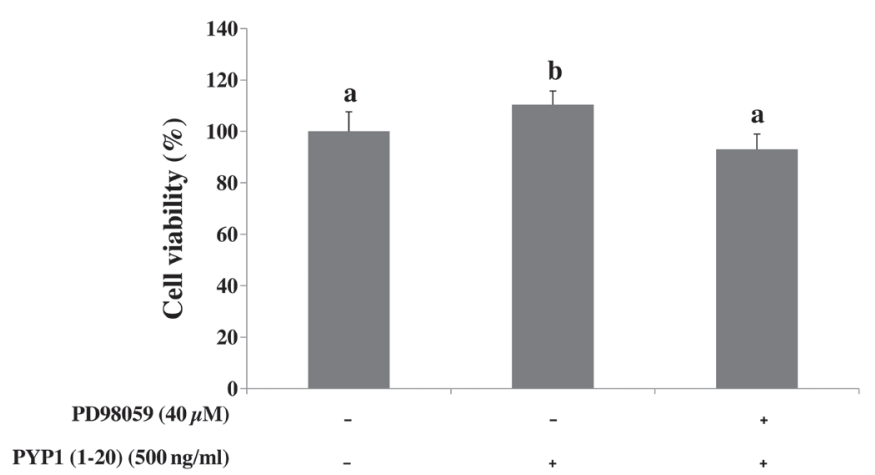

Figure 3. Effects of the MEK inhibitor (PD98059) on the Pyropia yezoensis peptide [PYP1 (1-20)]-induced proliferation of IEC- 6 cells. Cells were seeded in 96-well plates at $1 \times 10^{4}$ cells/well in $100 \mu 1$ medium. After $24 \mathrm{~h}$, the cells were maintained in SFM for $4 \mathrm{~h}$. Following pre-treatment with PD98059 (40 $\mu \mathrm{l})$, the cells were incubated with PYP1 (1-20) for $24 \mathrm{~h}$. Cell viability was measured using an MTS assay kit as per the manufacturer's instructions. Values represent the means \pm SD. Different letters indicate significant values according to Duncan's multiple range test.

expression levels of cyclin D1, cyclin E, Cdk2, Cdk4, Cdk6 and $\mathrm{pRb}$ increased, whereas those of p21 and p27 decreased following treatment with PYP1 (1-20) for $24 \mathrm{~h}$ (Fig. 5). These results suggest that PYP1 (1-20) promotes IEC-6 cell proliferation by modulating the cell cycle-related proteins.

\section{Discussion}

Many types of seaweed have received a great deal of attention from researchers in recent years for their high levels of nutrients, such as proteins, minerals, vitamins and polysaccharides. In particular, the anti-inflammatory and antitumor activities of seaweed have been studied extenstively $(24,25)$.

In a previous study, we demonstrated that treatment with PYP1 (1-20) promotes the proliferation of IEC-6 cells through insulin-like growth factor I receptor (IGF-IR) signaling pathways (7). In the present study, we investigated whether PYP1 (1-20) promotes IEC-6 cell proliferation and cell cycle progression through the EGFR signaling pathway.

The activation of EGFR has been detected in many different cell types, such as epithelial, nerve and mesenchymal cells $(14,15)$. EGFR activity induced by EGF binding has been implicated in essential cellular functions, including migration, differentiation, survival and proliferation $(12,23)$. Activated EGFR leads to the activation of downstream signaling pathways, such as the Ras-p42/p44 MAPK pathway. The Ras-p42/ p44 MAPK signaling cascade is a key mediator of growth factor-dependent cell survival, proliferation and differentiation (24). The activation of Ras occurs mostly via adaptor complex proteins containing Shc, Grb2 and SOS (16). In this study, PYP1 (1-20) increased the protein and mRNA expression levels of EGFR, Shc, Grb2 and SOS (Fig. 1). Therefore, we confirmed the effects of PYP1 (1-20) on the Ras-p42/p44 MAPK signaling pathway. Ras/Raf/MEK/ERK signaling commences at the cell surface, leading to the regulation of gene expression within the cell nucleus (6). In this study, in accordance with PYP1 (1-20)-induced cell proliferation, Ras, Raf, MEK and ERK, important mediators that regulate cell 

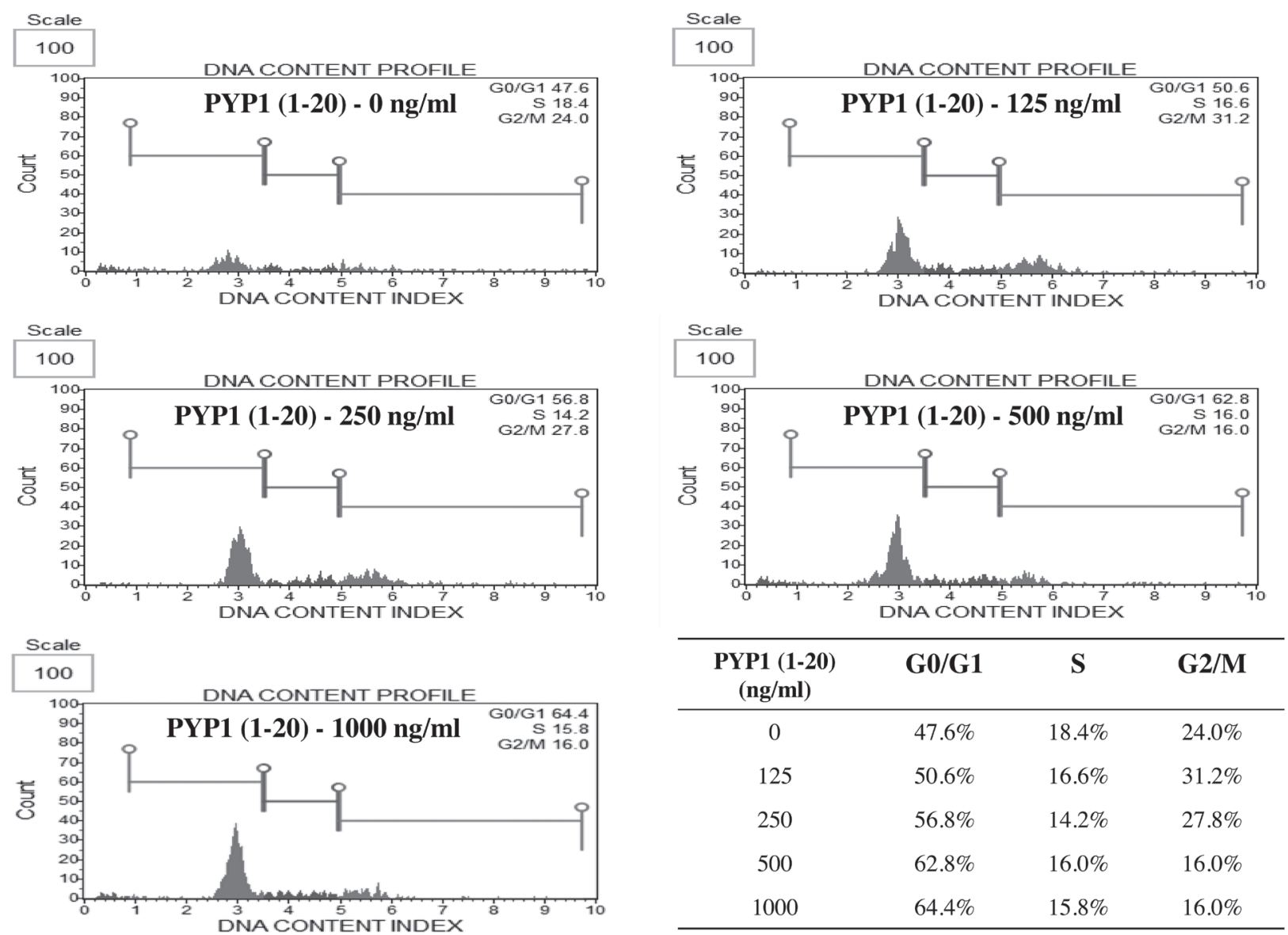

Figure 4. Treatment of IEC-6 cells with Pyropia yezoensis peptide [PYP1 (1-20)] resulted in cell cycle progression. In the dose dependence experiments, PYP1 (1-20) was added at varying concentrations $(125,250,500$ and $1,000 \mathrm{ng} / \mathrm{ml})$.

\section{A}

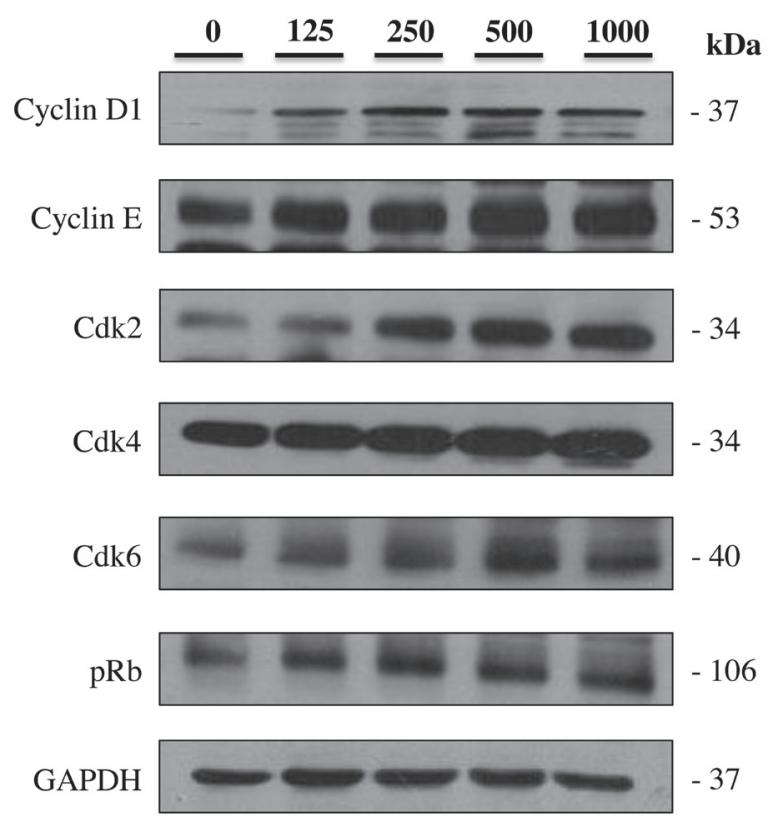

B

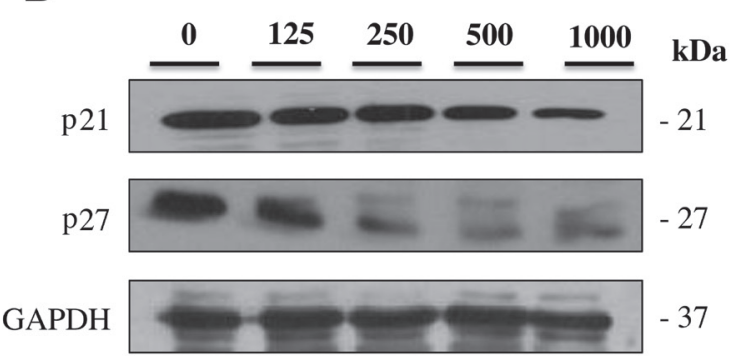

Figure 5. Effect of treatment with Pyropia yezoensis peptide [PYP1 (1-20)] on the levels of cell cycle-related proteins in IEC-6 cells. Cells were treated with PYP1 (1-20) after pre-incubation with SFM for $4 \mathrm{~h}$. Whole cell extracts were prepared and analyzed by western blot analysis using (A) anti-cyclin D1, anticyclin E, anti-Cdk2, anti-Cdk4, anti-Cdk6 and anti-pRb; and (B) anti-p21, anti-p27 and anti-glyceraldehyde 3-phosphate dehydrogenase (GAPDH) antibodies. 
survival, growth and proliferation, were activated by exposure to PYP1 (1-20) (Fig. 2).

PYP1 (1-20)-induced cell proliferation was examined by cell cycle analysis (Fig. 4). Treatment with PYP1 (1-20) markedly increased the proportion of cells in the G0/G1 phase from 47.6 to $64.4 \%$, suggesting that PYP1 (1-20) promotes cell cycle progression (Fig. 4). The PYP1 (1-20)-induced cell cycle progression resulted in cell proliferation and was related to the expression of cell cycle-related proteins, such as cyclin and Cdk. The expression levels of cyclin D1, cyclin E, Cdk2, Cdk4, Cdk6, $\mathrm{pRb}, \mathrm{p} 21$ and p27 were measured by western blot analysis. The expression levels of cyclin D1, cyclin E, Cdk2, Cdk4, Cdk6 and $\mathrm{pRb}$ were increased in a dose-dependent manner, whereas the expression levels of p21 and p27 decreased in a dose-dependent manner (Fig. 5). Thus, the PYP1 (1-20)-induced cell cycle progression resulted in IEC-6 cell proliferation.

In the present study, we demonstrate that PYP1 (1-20) mediates cell proliferation through an EGFR signaling pathway in IEC-6 cells. These findings suggest the significant role of EGFR in intestinal epithelial cell proliferation, as well as the potential role of PYP1 (1-20) as a bio-functional food with a proliferative effect on rat intestinal epithelial cells.

\section{Acknowledgements}

This study was supported by the Basic Science Research Program through the National Research Foundation of Korea (NRF) funded by the Ministry of Education (grant no. 2012R1A6A1028677).

\section{References}

1. Zhao Y, Wu J, Shang D, Ning J, Zhai Y, Sheng X and Ding H: Subcellular distribution and chemical forms of cadmium in the edible seaweed, Porphyra yezoensis. Food Chem 168: 48-54, 2015.

2. van Netten C, Hoption Cann SA, Morley DR and van Netten JP: Elemental and radioactive analysis of commercially available seaweed. Sci Total Environ 255: 169-175, 2000.

3. Dousip A, Matanjun P, Sulaiman MR, Tan TS, Ooi YBH and Lim TP: Effect of seaweed mixture intake on plasma lipid and antioxidant profile of hyperholesterolaemic rats. J Appl Phycol 26: 999-1008, 2014.

4. Jiang LF: The polysaccharides from Porphyra yezoensis suppress the denaturation of bighead carp myofibrillar protein. Int J Biol Macromol 68: 18-20, 2014.

5. Shin ES, Hwang HJ, Kim IH and Nam TJ: A glycoprotein from Porphyra yezoensis produces anti-inflammatory effects in liposaccharide-stimulated macrophages via the TLR4 signaling pathway. Int J Mol Med 28: 809-815, 2011.

6. Qian L, Zhou Y and Ma JX: Hypolipidemic effect of the polysaccharides from Porphyra yezoensis. Int J Biol Macromol 68: 48-49, 2014

7. Lee MK, Kim IH, Choi YH and Nam TJ: A peptide from Porphyra yezoensis stimulates the proliferation of IEC-6 cells by activating the insulin-like growth factor I receptor signaling pathway. Int J Mol Med 35: 533-538, 2015.
8. Song SH, Kim IH and Nam TJ: Effect of a hot water extract of Chlorella vulgaris on proliferation of IEC-6 cells. Int J Mol Med 29: 741-746, 2012.

9. Schlessinger J: Cell signaling by receptor tyrosine kinases. Cell 103: 211-225, 2000

10. Hubbard SR and Till JH: Protein tyrosine kinase structure and function. Annu Rev Biochem 69: 373-398, 2000.

11. Ostman A and Böhmer FD: Regulation of receptor tyrosine kinase signaling by protein tyrosine phosphatases. Trends Cell Biol 11: 258-266, 2001.

12. Sordella R, Bell DW, Haber DA and Settleman J: Gefitinibsensitizing EGFR mutations in lung cancer activate anti-apoptotic pathways. Science 305: 1163-1167, 2004.

13. DeYulia GJ Jr and Cárcamo JM: EGF receptor-ligand interaction generates extracellular hydrogen peroxide that inhibits EGFRassociated protein tyrosine phosphatases. Biochem Biophys Res Commun 334: 38-42, 2005.

14. Yu C, Hale J, Ritchie K, Prasad NK and Irudayaraj J: Receptor overexpression or inhibition alters cell surface dynamics of EGF-EGFR interaction: New insights from real-time single molecule analysis. Biochem Biophys Res Commun 378: 376-382, 2009.

15. Rajalingam K, Wunder C, Brinkmann V, Churin Y, Hekman M, Sievers C, Rapp UR and Rudel T: Prohibitin is required for Ras-induced Raf-MEK-ERK activation and epithelial cell migration. Nat Cell Biol 7: 837-843, 2005.

16. Holt KH, Waters SB, Okada S, Yamauchi K, Decker SJ, Saltiel AR, Motto DG, Koretzky GA and Pessin JE: Epidermal growth factor receptor targeting prevents uncoupling of the Grb2-SOS complex. J Biol Chem 271: 8300-8306, 1996.

17. Buday L, Egan SE, Rodriguez Viciana P, Cantrell DA and Downward J: A complex of Grb2 adaptor protein, Sos exchange factor, and a $36-\mathrm{kDa}$ membrane-bound tyrosine phosphoprotein is implicated in ras activation in T cells. J Biol Chem 269: 9019-9023, 1994.

18. Tidyman WE and Rauen KA: The RASopathies: Developmental syndromes of Ras/MAPK pathway dysregulation. Curr Opin Genet Dev 19: 230-236, 2009.

19. Ashton-Beaucage D, Udell CM, Gendron P, et al: A functional screen reveals an extensive layer of transcriptional and splicing control underlying RAS/MAPK signaling in Drosophila. PLoS Biol 12: e1001809, 2014.

20. Bonni A, Brunet A, West AE, Datta SR, Takasu MA and Greenberg ME: Cell survival promoted by the Ras-MAPK signaling pathway by transcription-dependent and -independent mechanisms. Science 286: 1358-1362, 1999.

21. Choi YH, Yamaguchi K, Oda T and Nam TJ: Chemical and mass spectrometry characterization of the red alga Pyropia yezoensis chemoprotective protein (PYP): Protective activity of the $\mathrm{N}$-terminal fragment of PYP1 against acetaminophen-induced cell death in Chang liver cells. Int J Mol Med 35: 271-276, 2015.

22. Kim YM, Kim IH and Nam TJ: Capsosiphon fulvescens glycoprotein reduces AGS gastric cancer cell migration by downregulating transforming growth factor- $\beta 1$ and integrin expression. Int J Oncol 43: 1059-1065, 2013.

23. Pardee AB: G1 events and regulation of cell proliferation. Science 246: 603-608, 1989.

24. Go H, Hwang HJ and Nam TJ: Polysaccharides from Capsosiphon fulvescens stimulate the growth of IEC-6 Cells by activating the MAPK signaling pathway. Mar Biotechnol (NY) 13: 433-440, 2011.

25. Hwang HJ, Kwon MJ, Kim IH and Nam TJ: Chemoprotective effects of a protein from the red algae Porphyra yezoensis on acetaminophen-induced liver injury in rats. Phytother Res 22: 1149-1153, 2008 